istence of an "H-bonded" association between adsorbed $\mathrm{O}_{2}$ and $\mathrm{N}_{2}$ and the $-\mathrm{OH}$ groups of a silica surface; (iii), the recent suggestion ${ }^{11-16}$ that a comparable $\mathrm{HBB}$ competitive complexation process controls the potency of fluorocarbon

(11) T. Di Paolo and C. Sandorfy, Nature (London), 252, 471 (1974).

(12) T. Di Paolo and C. Sandorfy, J. Med. Chem., 17, 809 (1974).

(13) T. Di Paolo and C. Sandorfy, Can J. Chem., 55, 1593 (1977).

(14) A. Nagyrévi and C. Sandorfy, Can. J. Chem., 55, 1593 (1977).

(15) R. Massuda and C. Sandorfy, Can. J. Chem., 55, 3211 (1977).

(16) G. Trudeau, K. C. Cole, R. Massuda, and C. Sandorfy, Can. J. Chem. 56, 1681 (1978) anesthetics; and (iv), the observed effects ${ }^{17}$ of $\mathrm{H}$-bonds donors on the glass transition temperature of linear alcohols.

Further work is underway and a longer report will be issued shortly.

Acknowledgment. This work was supported by the U.S. Department of Energy.

(17) A. V. Lesikar, J. Chem. Phys., 63, 2297 (1975).

\title{
Effect of Hydration on the Local Symmetry around Aluminum In ZSM-5 Zeolltes Studled by Aluminum-27 Nuclear Magnetic Resonance
}

\author{
A. P. M. Kenigens, K. F. M. G. J. Scholle, and W. S. Veeman* \\ Department of Physical Chemistry, University of Nijmegen, Toernoolveld, 6525 ED Nijmegen, The Netherlands (Received: June 8, 1983)
}

\begin{abstract}
The effect of hydration and dehydration on the electric field gradient at the ${ }^{27} \mathrm{Al}$ nucleus in ZSM-5 zeolites is investigated by magic angle spinning NMR at three different magnetic field strengths. The experiments show that dehydration causes an increase of the ${ }^{27} \mathrm{Al}$ NMR line width due to an increased quadrupole interaction. The dehydration therefore causes a redistribution of electric charges and/or a conformation change of the aluminum-oxygen tetrahedra. The latter possibility seems to be most important since the effect is cation dependent, as shown by results on Na-ZSM- 5 and H-ZSM- 5 . Similar effects have been observed for faujasite $\mathrm{H}-\mathrm{Y}$ and amorphous $\mathrm{SiO}_{2} / \mathrm{Al}_{2} \mathrm{O}_{3}$.
\end{abstract}

\section{Introduction}

Zeolites are crystalline aluminosilicates composed of silicon-oxygen and aluminum-oxygen tetrahedra. The negative charge of the aluminum-oxygen tetrahedra is neutralized by cations like $\mathrm{Na}^{+}$or $\mathrm{H}^{+}$. All zeolites display catalytic activity but especially the class of zeolites denoted by ZSM- 5 has received much interest recently due to its unique catalytic properties. ${ }^{1}$

Magic angle spinning proton NMR of H-ZSM-5 showed that at low water content two resonances are present, arising from water molecules chemisorbed at the Bronsted acidic site ( $\mathrm{Si}-\mathrm{OH}-\mathrm{Al})$ and from water molecules adsorbed at silanol groups, the terminating $\mathrm{Si}-\mathrm{OH}$ groups at the surface of the crystallites. ${ }^{2}$ It is believed that water molecules adsorbed at the Bronsted sites form clusters with the acidic proton: $\mathrm{H}^{+}\left(\mathrm{H}_{2} \mathrm{O}\right)_{n}$ where $n$ is of the order of $2 .^{3}$ Hydration and dehydration of $\mathrm{H}-\mathrm{ZSM}-5$ therefore is expected to slightly alter the position of the $\mathrm{H}^{+}$proton and consequently change the conformation of and the charge distribution around the aluminum-oxygen tetrahedron.

Aluminum has a nuclear spin $5 / 2$ and therefore a nuclear quadrupole moment which can interact with an electric field gradient at the site of the nucleus caused by surrounding ions. For a perfect tetrahedral surrounding of

(1) J. P. van den Berg, Thesis, Eindhoven, The Netherlands, 1981; P. B. Weisz, Pure Appl. Chem., 52, 2091 (1980); S. M. Csicsery in "Zeolite Chemistry and Catalysis", J. A. Rabo, Ed., American Chemical Society, Washington, DC, 1976, ACS Monogr., No. 171, p 680.

(2) (a) D. Freude, M. Hunger, and H. Pfeiffer, Chem. Phys. Lett., 91 307 (1982); (b) K. F. M. G. J. Scholle, W. S. Veeman, J. G. Post, and J. H. C. van Hooff, Zeolites, 3, 214 (1983).

(3) H. Nakamoto and H. Takahashi, Zeolites, 2,67 (1982); D. H. Olson, W. O. Haag, and R. M. Lago, J. Catal., 61, 390 (1980). aluminum by four oxygens, the electric field gradient is zero. Any distortion of this tetrahedron, however, should cause a field gradient at aluminum and consequently a quadrupole interaction of the aluminum nuclear spin.

In this letter we report results from magic angle spinning NMR of aluminum in Na-ZSM-5 and H-ZSM-5 which show unambiguously that hydration and dehydration affect the conformation of the aluminum-oxygen tetrahedra. Similar experiments on amorphous $\mathrm{SiO}_{2} / \mathrm{Al}_{2} \mathrm{O}_{3}$ and faujasite $\mathrm{H}-\mathrm{Y}$ show the same phenomenon, except that for aluminum in octahedral sites, present in amorphous $\mathrm{SiO}_{2} / \mathrm{Al}_{2} \mathrm{O}_{3}$, hydration or dehydration has no detectable effect on the field gradient at the aluminum nucleus.

\section{Experimental Section}

The Na-ZSM-5 (Si/Al ratio 40) and H-ZSM-5 (Si/Al ratio 15) were donated by DSM, Geleen; faujasite $\mathrm{H}-\mathrm{Y}$ ( $\mathrm{Si} / \mathrm{Al}$ ratio 2.5) and the amorphous $\mathrm{SiO}_{2} / \mathrm{Al}_{2} \mathrm{O}_{3}$ (HA HPV, $\mathrm{Si} / \mathrm{Al}$ ratio 2.4) are commercial samples from Union Carbide and AKZO Nederland, respectively. Dehydration of the samples was achieved by vacuum drying $\left(10^{-2}\right.$ torr $)$ at temperatures between 200 and $400{ }^{\circ} \mathrm{C}$ ("shallow-bed" treatment). To prevent rehydration, spinners are filled under an anhydrous nitrogen gas atmosphere in a glovebox. ${ }^{1} \mathrm{H}$ NMR measurements ${ }^{2 b}$ revealed that rehydration through the spinner walls during the experiment is negligible. Hydration was performed at room temperature by exposing the material in a closed system to a small container with water.

The magic angle spinning aluminum NMR experiments were carried out by straightforward $90^{\circ}$-pulse excitation in three different spectrometers: a Bruker CXP $300\left(\nu_{\mathrm{A} 1}\right.$ $=78.2 \mathrm{MHz} ; 90^{\circ}$ pulse duration, $5 \mu \mathrm{s} ;$ repetition time, 0.2 
s), a home-built $180-\mathrm{MHz}$ spectrometer $\left(\nu_{\mathrm{Al}}=46.9 \mathrm{MHz}\right.$; $90^{\circ}$ pulse duration, $8 \mu \mathrm{s}$; repetition time, $0.5 \mathrm{~s}$ ), and a home-built $60-\mathrm{MHz}$ spectrometer $\left(\nu_{\mathrm{Al}}=15.6 \mathrm{MHz} ; 90^{\circ}\right.$ pulse duration, $8 \mu \mathrm{s}$; repetition time, $0.5 \mathrm{~s}$ ). The repetition times give full relaxation because $T_{1}$ values are of the order of $10 \mathrm{~ms}$. For all three spectrometers the same spinner was used, a cylindrical Delrin spinner supported by two air bearings. ${ }^{4}$ A spinning frequency of $\sim 3 \mathrm{kHz}$ proved to be sufficient.

\section{Magic Angle Spinning NMR of a Quadrupolar Nucleus}

Aluminum nuclear spins in an aluminosilicate are subjected to three anisotropic inteactions: dipolar interactions with neighboring nuclei like ${ }^{1} \mathrm{H}$ and ${ }^{29} \mathrm{Si}$, interaction of the nuclear quadrupole moment with electric field gradients, and the anisotropic chemical shift interaction. Of these three interactions the quadrupole interaction will prove to be the most important for our experiments. A discussion of the effect of magic angle spinning on the NMR spectra of quadrupolar nuclei can be found at several places in the literature. ${ }^{5}$ Here we want to mention only the outcome of these theories.

For half-integer nuclear spins like ${ }^{27} \mathrm{Al}$, the anisotropic quadrupole interaction causes a severe line broadening in solid-state NMR spectra, except for the $m=1 / 2 \leftrightarrow m=$ $-1 / 2$ transition if the quadrupole interaction is small compared to the Zeeman interaction of the nuclear spin. It is easy to show that for this $1 / 2 \leftrightarrow-1 / 2$ transition the quadrupole interaction contributes only in second- and higher-order perturbation theory. ${ }^{6}$ In practice, therefore, only this transition is observed in solid samples, showing a characteristic powder pattern depending on the value of the asymmetry parameter $\eta ;{ }^{7}$ magic angle spinning reduces but does not eliminate the width of this powder pattern. A formula for the frequency of the $1 / 2 \leftrightarrow-1 / 2$ transition under fast magic angle spinning conditions has been derived by Kundla et al. ${ }^{5 \mathrm{~b}}$ and can be rewritten as

$$
\begin{aligned}
& \nu_{1 / 2,-1 / 2}=\nu_{z}- \\
& \frac{1}{16} \frac{\nu_{Q}^{2}}{\nu_{z}}\left\{I(I+1)-\frac{3}{4}\right\}\left\{A(\alpha) \cos ^{4} \beta+B(\alpha) \cos ^{2} \beta+C(\alpha)\right\}
\end{aligned}
$$

where

$$
\begin{gathered}
\nu_{z}=-\gamma B_{0}\left(1-\sigma_{\mathrm{j}}\right) / 2 \pi \\
\nu_{\mathrm{Q}}=3 e^{2} q Q /\{2 I(2 I-1) h\} \\
A(\alpha)=7 / 2-7 / 3 \eta \cos 2 \alpha+(7 / 18) \eta^{2} \cos ^{2} 2 \alpha \\
B(\alpha)=-3+\frac{2}{9} \eta^{2}+8 / 3 \eta \cos 2 \alpha-7 / 9 \eta^{2} \cos ^{2} 2 \alpha \\
C(\alpha)=5 / 6-1 / 3 \eta \cos 2 \alpha+(7 / 18) \eta^{2} \cos ^{2} 2 \alpha
\end{gathered}
$$

and $\alpha$ and $\beta$ are the polar angles of the spinning axis with respect to the principal axes of the quadrupole tensor.

Singular points and discontinuities in the powder pattern are found when $\partial \nu_{1 / 2,-1 / 2} / \partial \alpha=\partial \nu_{1 / 2,-1 / 2} / \partial \beta=0$. Figure

(4) P. A. S. van Dijk, W. Schut, J. W. M. van Os, E. M. Menger, and W. S. Veeman, J. Phys. E, 13, 1309 (1980)

(5) (a) M. Maricq and J. S. Waugh, J. Chem. Phys., 70, 3300 (1979); (b) E. Kundla, A. Samoson, and E. Lippmaa, Chem. Phys. Lett., 83, 229 (1981); (c) A. Samoson, E. Kundla, and E. Lippmaa, J. Magn. Reson., 49, 350 (1982); (d) S. Ganapathy, S. Schramm, and E. Oldfield, J. Chem. Phys., 77, 4360 (1982).

(6) A. Abragam, "The Principles of Nuclear Magnetism", Oxford University Press, London, 1961.

(7) J. F. Baucher, P. C. Taylor, T. Oja, and P. J. Bray, J. Chem. Phys., 50, 4914 (1969).

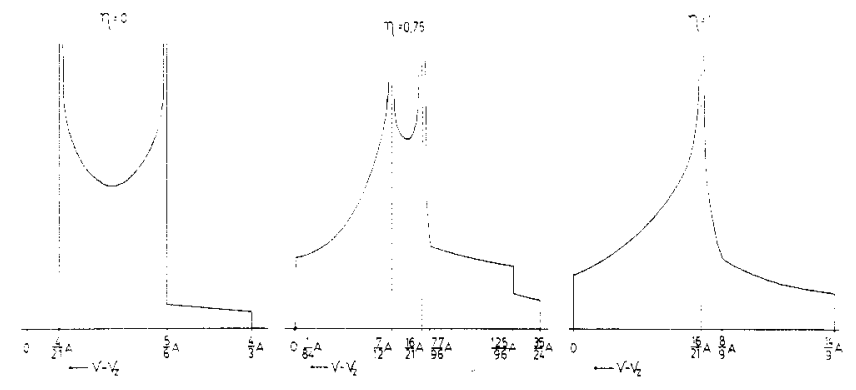

Figure 1. Theoretical line shape of $1 / 2 \leftrightarrow-1 / 2$ transition of quadrupolar nuclear spin in a powder with fast magic angle spinning for different values of the asymmetry parameter $\eta ; A=-(1 / 16)\left(\nu_{0}^{2} / \nu_{z}\right)(I(I+1)$ $-3 / 4$ ).

\section{HYDRATED DEHYDRATED}

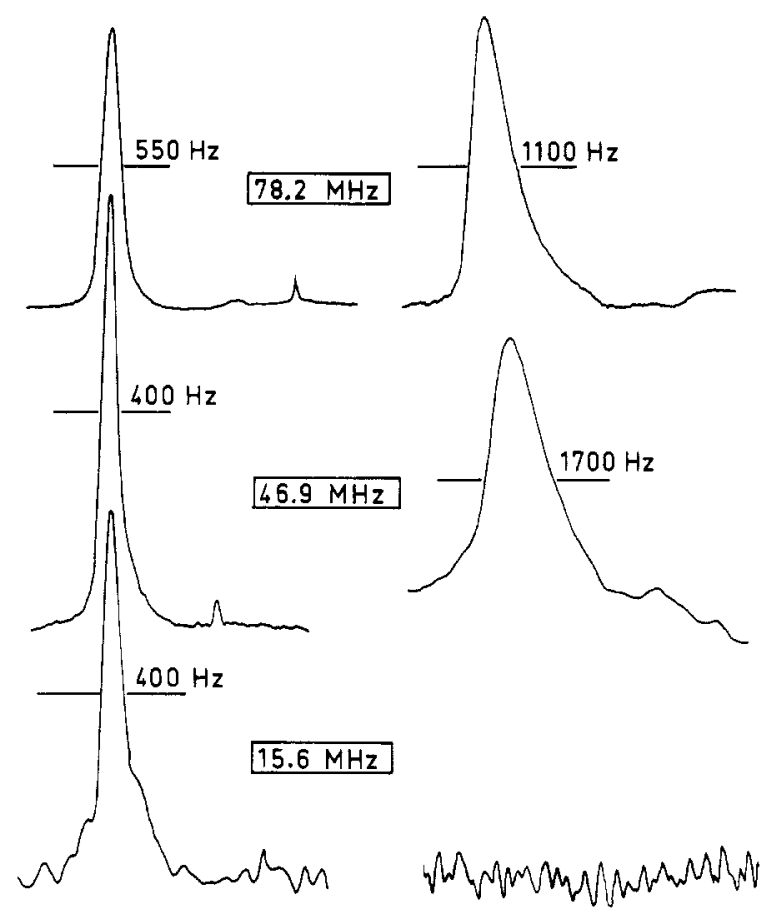

Figure 2. ${ }^{27} \mathrm{Al}$ spectra of $\mathrm{H}-\mathrm{ZSM}-5$ at three different magnetic fields at $78.2,46.9$, and $15.6 \mathrm{MHz}$ with $3-\mathrm{kHz}$ magic angle spinning. All spectra are obtained at room temperature. The hydrated spectra are the result of 10000 (at $78.2 \mathrm{MHz}$ ), 130000 (at $46.9 \mathrm{MHz}$ ), and 350000 (at $15.6 \mathrm{MHz}$ ) fld's. The spectra of the dehydrated material needed 250000 (at $78.2 \mathrm{MHz}$ ) and 180000 (at $46.9 \mathrm{MHz}$ ) fid's. At $15.6 \mathrm{MHz}$ no signal was obtained of the dehydrated material after 750000 fid's.

1 shows the pattern for $\eta=0, \eta=0.75$, and $\eta=1$. Equation 1 shows in addition that the width of powder pattern decreases with magnetic field. Therefore, when in an experimental situation it is found that the line width of a line decreases with field, then this points to the existence of quadrupole broadening. This is in contrast to a broadening due to a distribution of chemical shifts, a common source of line broadening in magic angle spinning NMR, which increases with field.

\section{Results and Discussion}

Figure 2 shows ${ }^{27} \mathrm{Al}$ spectra of $\mathrm{H}-\mathrm{ZSM}-5$ at three different frequencies for the hydrated and dehydrated form. For the hydrated samples the line width first decreases from $550 \mathrm{~Hz}$ at $78.2 \mathrm{MHz}$ to $400 \mathrm{~Hz}$ at $46.9 \mathrm{MHz}$ and then remains constant at $15.6 \mathrm{MHz}$. The initial decrease of this line width with field shows that for the hydrated samples quadrupole broadening is certainly not the most important factor determining the line width at $78.2 \mathrm{MHz}$. As the 


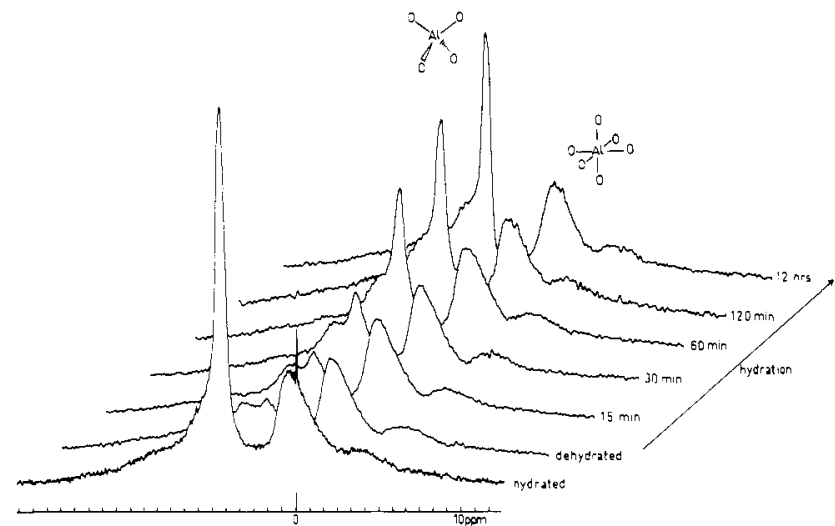

Figure 3. ${ }^{27} \mathrm{Al}$ spectra of $\mathrm{Na}-\mathrm{ZSM}-5$ as a function of water content at $78.2 \mathrm{MHz}$. All spectra represent 25000 fld's and are obtained with $3-\mathrm{kHz}$ magic angle spinning.

chemical shift anisotropy is eliminated by magic angle spinning, the initial decrease of the line width has to be due to the fact that the line width is caused by a distribution of ${ }^{27} \mathrm{Al}$ chemical shifts. Only at the lowest fields, where the chemical shift distribution in frequency units is small, does the quadrupole broadening become important. At frequencies below $15 \mathrm{MHz}$ the line width is expected to increase again.

For the dehydrated samples, however, the situation is very different. Figure 2 shows that the line width increases from $1100 \mathrm{~Hz}$ at $78.2 \mathrm{MHz}$ to $1700 \mathrm{~Hz}$ at $46.9 \mathrm{MHz}$ to undetectably broad at $15.6 \mathrm{MHz}$. Dehydration clearly makes the ${ }^{27} \mathrm{Al}$ line broader, by a factor 2 at $78.2 \mathrm{MHz}$, by a factor 4 at $46.9 \mathrm{MHz}$, and by a much larger factor at 15.6 $\mathrm{MHz}$. The field dependence of the line width shows that quadrupole interaction is the dominant factor determining the line width in the dehydrated samples. Clearly, dehydration causes a strong increase of the quadrupole interaction.

By comparing the experimental line shapes to the theoretical shapes of Figure 1, one can conclude that the resulting electric field gradient at aluminum is highly asymmetric (no separate quadrupole pairs are observed). At this point we should mention that proton decoupling during acquisition of the $\mathrm{Al}$ free induction decay does not affect the Al NMR line width, not in the hydrated case nor in the dehydrated situation. Dipolar interaction between protons and $\mathrm{Al}$ apparently is so weak that it can be eliminated by magic angle spinning alone.

Figure 3 displays ${ }^{27} \mathrm{Al}$ spectra of $\mathrm{Na}-\mathrm{ZSM}-5$ as a function of the water content. These spectra show not only a line at $53 \mathrm{ppm}$ but in addition lines at 65,5 , and $-1 \mathrm{ppm}$ (relative to $\mathrm{Al}\left(\mathrm{H}_{2} \mathrm{O}\right)_{6}{ }^{3+}$ ). The aluminum coordination can be determined on the basis of these chemical shift data. ${ }^{8}$ The line at $53 \mathrm{ppm}$ of four-coordinated $\mathrm{Al}$ is attributed to $\mathrm{Al}$ in the ZSM-5 lattice. The narrow line at $-1 \mathrm{ppm}$ originates from six-coordinated $\mathrm{Al}$, presumably $\mathrm{Al}\left(\mathrm{H}_{2} \mathrm{O}\right)_{6}{ }^{3+}$ in the pores. The broader lines at 65 and $5 \mathrm{ppm}$, from fourand six-coordinated aluminum, must be due to an impurity or lattice defects. Because of the resemblance of these lines with spectra of $\mathrm{Al}_{2} \mathrm{O}_{3}{ }^{9}$ this might be an aluminum oxide impurity. X-ray analysis of this sample, however, did not reveal any impurity, presumably because the disordered regions are very small. Recently the existence of Al-rich non-zeolite material, which could not be detected by X-ray

(8) D. Müller, W. Gessner, H.-J. Behrens, and G. Scheler, Chem. Phys. Lett., 79, 59 (1981).

(9) (a) V. M. Mastikhin, O. P. Krivoruchko, B. P. Zolotovskii, and R. A. Buyanov, React. Kinet. Catal. Lett., 18, 117 (1981); (b) C. S. John, N. C. M. Alma, and G. R. Hays, Appl. Catal., 6, 341 (1983).

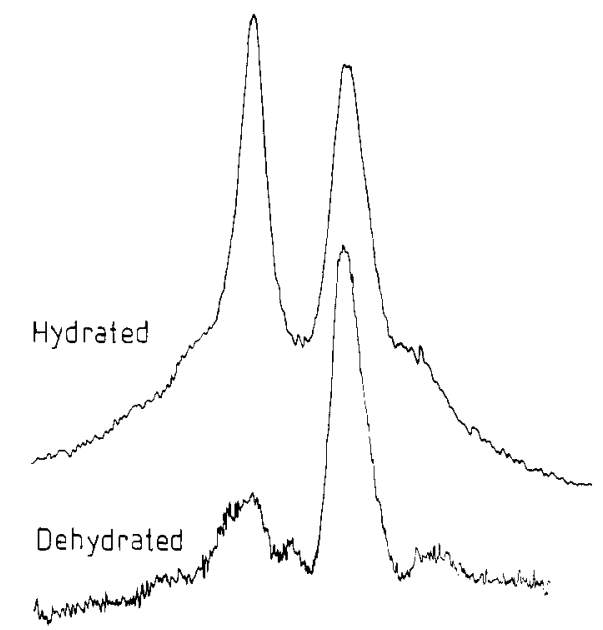

100

PPT

Flgure 4. ${ }^{27} \mathrm{Al}$ spectra of amorphous $\mathrm{SiO}_{2} / \mathrm{Al}_{2} \mathrm{O}_{3}$ at $78.2 \mathrm{MHz}$ with $3-\mathrm{kHz}$ magic angle spinning. The spectrum of the hydrated form represents 25000 fid's, and that of the dehydrated form 50000 fid's.

diffraction, is also reported by Hughes et al. ${ }^{10}$

When the sample is dried at $250^{\circ} \mathrm{C}$, the tetrahedral $\mathrm{Al}$ line at $53 \mathrm{ppm}$ collapses; hydration for a variable length of time makes this line slowly appear again. In the dehydrated sample, evidently, the quadrupole interaction becomes so strong that the tetrahedral $\mathrm{Al}$ line of the genuine ZSM-5 aluminum becomes too broad to be detectable, even at $78.2 \mathrm{MHz}$. Apparently, the increase of quadrupole interaction on dehydration is much stronger for Na-ZSM-5 than for H-ZSM-5. Dehydration of the Na-ZSM-5 sample has no effect on the broad lines at 5 and $65 \mathrm{ppm}$; the narrow line at $-1 \mathrm{ppm}$ disappears and does not come back at hydration.

The same experiments were carried out on faujasite $\mathrm{H}-\mathrm{Y}$ and amorphous $\mathrm{SiO}_{2} / \mathrm{Al}_{2} \mathrm{O}_{3}$. For faujasite $\mathrm{H}-\mathrm{Y}$ the situation is just the reverse of that for ZSM-5: the Al line width of the hydrated sample increases on going to the lower frequency ( $750 \mathrm{~Hz}$ at $78.2 \mathrm{MHz}, 1350 \mathrm{~Hz}$ at 46.9 $\mathrm{MHz}$ ). Apparently, even in the hydrated form there is already a considerable broadening due to quadrupole interaction, showing the existence of distorted tetrahedra. This distortion may be inherent to the structure which is different from H-ZSM-5, and possibly due to the presence of aluminum in higher coordination spheres (faujasite $\mathrm{H}-\mathrm{Y}$ has a $\mathrm{Si}-\mathrm{Al}$ ratio of 2.5 !). On dehydration the faujasite $\mathrm{H}-\mathrm{Y}$ Al line width at $78.2 \mathrm{MHz}$ increases to $1800 \mathrm{~Hz}$, showing a considerable extra distortion around aluminum.

Figure 4 shows the ${ }^{27} \mathrm{Al}$ spectrum of amorphous $\mathrm{SiO}_{2} /$ $\mathrm{Al}_{2} \mathrm{O}_{3}$ at $78.2 \mathrm{MHz}$ for hydrated and dehydrated material. Only the peak at $\sim 52 \mathrm{ppm}$ from tetrahedrally surrounded aluminum broadens on dehydration, indicating that strong chemisorption of water takes place only at the tetrahedral sites, not at octahedrally coordinated aluminum.

As a conclusion of this work we can then state that in both Na-ZSM-5 and H-ZSM-5 dehydration causes a lowering of local symmetry around aluminum as evidenced by the increase in quadrupole interaction of aluminum. This increase is cation dependent. Similar effects are observed in faujasite $\mathrm{H}-\mathrm{Y}$ and amorphous $\mathrm{SiO}_{2} / \mathrm{Al}_{2} \mathrm{O}_{3}$. On the crucial question of what precisely causes this lowering of local symmetry, we can at this moment only speculate. As mentioned in the Introduction it is believed that in

(10) A. E. Hughes, K. G. Wilshier, B. A. Sexton, and P. Smart, J. Catal., 80, 221 (1983). 
hydrated material the cation forms a cluster with water molecules. On dehydration the cation presumably comes nearer to aluminum. This causes a change in the distribution of charges around aluminum and possibly a distortion of the aluminum-oxygen tetrahedra. Both effects, the change in charge distribution and distortion of the tetrahedron, can give rise to an increase electric field gradient at the aluminum nucleus. However, from the observation that the increase in quadrupole interaction on dehydration is stronger for Na-ZSM-5 than for H-ZSM-5, we tend to believe that the distortion of the tetrahedra is more important for the increased electric field gradient than the redistribution of charges, although of course the latter effect may induce the local distortions.

In the case of dehydrated $\mathrm{H}-\mathrm{ZSM}-5$ it is often indicated that the $\mathrm{H}^{+}$ion exists in a $\mathrm{Al}-\mathrm{O}^{-} \mathrm{H}^{+}$band. For a perfect tetrahedron with an $\mathrm{Al}-\mathrm{O}$ distance of $1.59 \AA$ and an $\mathrm{O}-\mathrm{H}$ distance of $1 \AA$, the dipolar interaction between $\mathrm{Al}$ and $\mathrm{H}$ would give rise to a broadening of the Al NMR line of 2300
Hz. Such a broadening, however, is not observed, suggesting either that the $\mathrm{Al}-\mathrm{H}^{+}$distance is much larger or that the $\mathrm{H}^{+}$ion is mobile.

Finally, we want to comment on the statement made earlier in this paragraph that in hydrated $\mathrm{H}-\mathrm{ZSM}-5$ the ${ }^{27} \mathrm{Al}$ line width is caused by a distribution of ${ }^{27} \mathrm{Al}$ chemical shifts. Preliminary ${ }^{27} \mathrm{Al}$ spin-lattice relaxation $\left(T_{1}\right)$ experiments clearly reveal several species with distinct $T_{1}$ values and distinct chemical shift. Further investigations are needed to establish the origin of these different ${ }^{27} \mathrm{Al}$ sites which together form the line shapes discussed in this paper.

Acknowledgment. We thank DSM, Geleen, for providing the ZSM-5 samples and Prof. Dr. E. de Boer, Dr. G. P. M. van der Velden, Ir, P. Frenken, Ir. J. de Haan, and Dr. E. Duynstee for discussions. This work is supported by DSM Research, Geleen, The Netherlands.

Registry No. Aluminum, 7429-90-5.

\title{
Exponentlal Fluorescence Decay from Single Rovibratlonal Levels of $S_{1}$ Acetaldehyde
}

\author{
Marcus Noble and Edward K. C. Lee* \\ Department of Chemistry, University of Calffornia, Irvine, Calfornia 92717 (Received: July 19, 1983)
}

Single rotational level $\mathrm{S}_{1}$ emission has been observed for jet-cooled acetaldehyde and $\alpha$-monodeuterated acetaldehyde. All the levels studied (up to $E_{\text {vib }}=1760 \mathrm{~cm}^{-1}$ ) yielded single exponential decays, the vibronic origin being the longest-lived levels $\left(\mathrm{CH}_{3} \mathrm{CHO}, 220 \mathrm{~ns} ; \mathrm{CH}_{3} \mathrm{CDO}, 1.52 \mu \mathrm{s}\right)$. The data are correlated with previous room temperature studies.

\section{Introduction}

Acetaldehyde is a molecule of atmospheric significance ${ }^{1}$ as well as a possible model for the photochemical and kinetic behavior of larger aldehydes. ${ }^{2}$ Because it is a seven-atom molecule with 15 vibrational degrees of freedom and small rotational constants $\left(A^{\prime \prime}=1.8870, B^{\prime \prime}=\right.$ $\left.0.3387, C^{\prime \prime}=0.3033 \mathrm{~cm}^{-1}\right),{ }^{3}$ the room temperature electronic spectrum is too congested to obtain detailed rovibrational information. In spite of this congestion, the weak nature of the $S_{1} \leftarrow S_{0}$ transition, and the less than unity quantum yield for fluorescence, several attempts have been made to study its $S_{1}$ dynamics by absorption and emission spectroscopic measurements. $2,4,5$

A recently reported experiment by Speiser et al. is the closest to a single vibrational level collision-free study. ${ }^{6}$ In this experiment an unnarrowed frequency doubled dye laser (fwhm $>1 \mathrm{~cm}^{-1}$ ) was used to excite low-pressure ( $\geq$ $25 \mathrm{mtorr}$ ) acetaldehyde vapor at $320 \mathrm{~nm}$. This wavelength was arbitrarily chosen to lie below the predissociative threshold $\left(\geq 31250 \mathrm{~cm}^{-1}\right){ }^{7}$ These authors reported the first observance of biexponential decay for $S_{1}$ acetaldehyde

(1) See, for an example, B. J. Finlayson and J. N. Pitts, Jr., Science, 192, 111 (1976).

(2) D. A. Hansen and E. K. C. Lee, J. Chem. Phys., 63, 3272 (1975)

(3) R. W. Kilb, C. C. Lin, and E. B. Wilson, J. Chem. Phys., 26, 1695 (1957)

(4) C. S. Parmenter and W. A. Noyes, Jr., J. Am. Chem. Soc., 85, 416 (1963).

(5) A. Gandini and P. A. Hackett, Chem. Phys. Lett., 52, 107 (1977).

(6) S. Speiser, W. F. Pfeiffer, and G. H. Atkinson, Chem. Phys. Lett., 93, $480(1982)$.

(7) R. J. Gill and G. H. Atkinson, Chem. Phys. Lett., 64, 426 (1979), (at 25 mtorr: $\tau_{\text {fast }} \sim 29 \mathrm{~ns}, \tau_{\text {slow }} 94 \mathrm{~ns}$ ) and estimated the fluorescence quantum yield as $7.5 \times 10^{-2}$, whereas a prior study ${ }^{2}$ in our laboratory found the longest lifetime at 10 torr to be $3.7 \mathrm{~ns}$ at $325 \mathrm{~nm}$. The biexponential decay observed by Speiser et al. was found to be pressure dependent: the slow component was preferentially quenched upto 400 mtorr (self-quenching rate coefficient: $6.7 \times 10^{7}$ torr $^{-1} \mathrm{~s}^{-1}$ ) at which pressure the decay appeared single exponential. Above $\mathbf{4 0 0}$ mtorr the decay continued to be self-quenched at the same rate. The authors attributed this overall behavior to the process of rapid reversible intersystem crossing followed by internal conversion. This is a model which has been introduced and used to explain the same behavior in $\alpha$-dicarbonyls by Kommandeur and co-workers. ${ }^{8}$

As part of our overall studies into the dynamics of small molecules in electronically excited states, we have observed the laser-induced fluorescence decay from single rovibrational levels of $S_{1}$ acetaldehyde and $\alpha$-monodeuterated acetaldehyde. The assignment of these levels was known from our acetaldehyde $\left(\mathrm{CH}_{3} \mathrm{CDO}\right)$ rovibronic analysis of the $\pi^{*} \leftarrow \mathrm{n}$ transition of acetaldehyde and its deuterated derivatives. ${ }^{9,10}$ The fluorescence lifetimes of these levels show interesting mode specificity and energy dependence which will be reported in detail elsewhere. ${ }^{10}$ We report

(8) (a) R. van der Werf, E. Schutten, and J. Kommandeur, Chem. Phys., 11, 281 (1975). (b) R. van der Werf and J. Kommandeur, ibid., 16, 125 (1976). (198) $\mathrm{M}$.

(10) M. Noble and E. K. C. Lee, results on the spectroscopy and dynamics of $\mathrm{CH}_{3} \mathrm{CHO}$ and deuterated molecules to be published. 